Peer-Reviewed Article

ISSN: 2162-3104 Print/ ISSN: 2166-3750 Online

Volume 6, Issue 4 (2016), pp. 873-886

(C) Journal of International Students

http://jistudents.org/

\title{
Helping the Transition: Mentorship to Support International Students in Canada
}

\author{
Clint Thomson \\ The University of Western Ontario, Canada \\ Victoria M. Esses \\ The University of Western Ontario, Canada
}

\begin{abstract}
We developed a program that paired newcomer international students with Canadian student mentors. These pairs met weekly throughout a semester and international student participants completed measures at both the beginning and end of the program. We found that program participants experienced positive changes in sociocultural and psychological adaptation, and a reduction in acculturative stress over time. At the conclusion of the program, program participants also showed higher levels of psychological adaptation and lower levels of acculturative stress than control participants, who had not participated in the program. These findings make an important contribution to the empirical literature on the acculturation of international students and provide foundations for future research.
\end{abstract}

Keywords: Acculturation, acculturative stress, mentorship, psychological adaptation, sociocultural adaptation

In 2014, there were over 5 million international students studying worldwide (ICEF Monitor 2015). This number has tripled over the past quarter century (ICEF Monitor, 2015) and is expected to reach over 7 million by the year 2025 (Bohm, Davis, Meares, \& Pearce, 2002). Canada has been no exception to this increase in international students as there were 22,000 international undergraduate students enrolled in Canada in 2000, and 89,000 in 2014 (Association of Universities and Colleges of Canada, 2014). In this context, it is important to understand the types of supports that can contribute to the adaptation of international students so that they flourish. 
One such program involves mentorship in which international students are paired with host-national students.

\section{LITERATURE REVIEW}

\section{Definitions}

As international students transition to life in the host culture in countries like Canada, they undergo the process of acculturation, defined by Sam (2006) as "all changes following contact between individuals of different groups or backgrounds,” (p. 11). Scholars studying the psychology of acculturation, and in particular, the acculturation of international students, have identified two primary domains of acculturation, psychological and sociocultural (e.g. Ward, Bochner, \& Furnham, 2001; Ward \& Kennedy, 1993). Furthermore, the term adaptation describes the stable changes that happen as a result of the acculturation experience. Thus, in investigations of the acculturation of international students, one can study both psychological and sociocultural adaptation. Psychological adaptation refers to newcomers' psychological well-being in the new environment (Berry, 2006), while sociocultural adaptation, on the other hand, is a newcomer's instrumental ability to negotiate day-to-day social tasks in the new culture (Masgoret \& Ward, 2006).

\section{Predominance of correlational literature}

A large portion of the past literature on the acculturation of international students has been correlational. In their review of two decades of this literature, Zhang and Goodson (2011) found that higher acculturative stress, stress associated with making a cross-cultural transition, was predictive of more negative psychological outcomes. However, Ying and Han (2006) found that for Taiwanese students in the United States, more contact with host-national students (American students) reduced acculturative stress 14 months after the arrival of the international students. As for sociocultural adaptation, Li and Gasser (2005) found that the amount of contact that international students had with host-national students (students who were natives of the host country) was positively related to their cross-cultural social efficacy. Also, Hechanova-Alampay, Beehr, Christiansen, and Van Horn (2002) found that international students who reported a greater degree of contact with host-national students reported better adjustment to the new environment. Finally, Rasmi, Safdar, and Lewis (2009) found that international students who formed more connections with Canadian students experienced better sociocultural adaptation 18 months after arrival in Canada. 


\section{Existing studies on peer-mentorship programs}

While it appears that friendships with host-national students can have substantial positive outcomes for both the social and psychological domains of international students' acculturation, experimental research is needed to establish directional linkages between friendships with hosts and these outcomes. A small number of studies have used quasi-experimental research designs to examine the influence of friendships with host students on international student outcomes in North America and Australia. Westwood and Barker (1990) paired newly arrived international students with peer mentors from the host-national undergraduate body and these pairs were encouraged to meet at least twice per month. International students who participated in the program achieved higher grades and were less likely to drop out of the university in comparison to students who did not participate in the program. Abe, Talbot, and Geelhoed (1998) examined the influence of a peer-mentorship program on various aspects of international student adjustment to university. They found that, in comparison to students who did not participate, international students in the program reported better social adjustment to university. Gresham and Clayton (2011) developed a program for international students and found that the students indicated that the most positive outcome of program participation was an improvement in their English proficiency and further development of friendships with host-national students. Woods et al. (2013) found that international students participating in a mentorship program experienced a positive change in the amount of time they spent with people from outside of their own ethnic group over a five-week period, relative to control participants, who did not experience a change.

\section{The low incidence of international student friendships with hosts}

Integrating the correlational literature with these results on peermentorship programs, it would appear that initiatives pairing international students with host students could improve both the social and psychological adaptation outcomes for international students. However, irrespective of the extent to which friendships with host students might help international students, there are data which suggest that these friendships do not easily form. A survey from the Canadian Bureau of International Education (CBIE) revealed that over half of 3,000 international students surveyed in Canada reported having no Canadian friends (CBIE, 2015). While there could be a myriad of factors impacting whether international and Canadian students can connect, this report suggested that in addition to language difficulties, many group activities for international students on campus (i.e. international organizations, diversity events), do not involve host students, and can thus provide ample opportunity to meet fellow international students from other countries, but not host students. The CBIE report also 
suggested that certain academic programs may in fact be mostly composed of international students, and thus also limit the opportunity to form connections with hosts.

\section{The present work}

Considering the literature on the acculturation of international students and their lack of friendships with host students, which, given the past literature, are highly beneficial for their social and psychological outcomes, the present study sought to address two primary issues. First, addressing the acculturation literature and the small number of studies on peer-mentorship programs, we endeavored to investigate the potential link between friendships with host students and better social and psychological adaptation for international students. Indeed, a recent comprehensive literature review recommends that more studies are needed that can assess the effectiveness of interventions like peer-mentorship programs on an array of social and psychological outcomes (Smith \& Khawaja, 2011). Second, we hoped to facilitate the occurrence of friendships between international and host students, which may not arise naturally on campus. If universities are now prioritizing internationalization, with more international students arriving every year (AUCC, 2014), it is imperative that they are equipped with current data that can inform them as to how to optimize the social experiences of international students once they arrive. The results of the present study could thus provide some insight as to a straightforward way by which to enrich campus social climates in the face of internationalization.

\section{RESEARCH METHOD}

In conducting this research, we recruited international student participants from a language-upgrading academic program at a large university in Eastern Canada. We then paired each of these students with a mentor, a host-Canadian student. Mentors were recruited from the undergraduate body at the university through social media and a volunteer website. Once created, the same-gender, mentor-mentee pairs were encouraged to meet weekly for the duration of at least one semester, explore campus, the local community, and practice conversational English. We also organized larger group events every 3-4 weeks that were held to ensure that all mentormentee pairs were meeting regularly. These events provided all members of the program (both mentors and mentees) the chance to socialize with one another over snacks and language games. We piloted this program from January to April 2015, and conducted the program again from September to December 2015. 


\section{Pilot program}

Piloting the program provided information to help us maximize the effectiveness of the mentorship program and develop methods to evaluate it. We conducted focus group interviews with pilot participants to better understand their experiences, which provided several key insights. First, international students voiced that they felt integrated at university in the sense that they were able to access the same campus facilities as Canadian students. However, these students also stated that they had difficulty forming deeper or more meaningful social connections with Canadian students because they felt they lacked knowledge of Canadian culture. The mentorship program was a helpful medium for the students to begin to develop the cultural knowledge they felt was so important in socializing with Canadian students. Because these international students indicated that they had difficulty forming social connections with Canadian students and we expected that the mentorship program might help in this regard, we determined that outcome measures from the acculturation literature sociocultural adaptation, acculturative stress, and psychological adaptation could be used to examine the potential benefits that international students might gain from the mentorship program, and thus, serve as relevant indicators of program effectiveness.

\section{Participants}

In September 2015, we recruited 25 international student participants from a language upgrading academic program for our mentorship program, and the participants who signed up for the program completed survey measures at two times, Time 1 in late-September, and again at Time 2, in mid-December. Overall, the program sample consisted of 11 males and 14 females, who had been in Canada for an average of 7.72 months. Sixteen of these participants were from China, five were from Brazil, one was from Korea, one from Qatar, one from Angola, and one from Venezuela. The control sample consisted of 16 males and 6 females, who had been in Canada for an average of 9.68 months. All but two of the control participants were from China with one from Libya, and one from the Democratic Republic of Congo.

\section{Measures}

We developed measures for sociocultural adaptation, psychological adaptation, and acculturative stress, while referring to the empirical literature on international students. To measure Sociocultural Adaptation, we used an 8-item scale with items drawn from the Social Situations Questionnaire (Furnham \& Bochner, 1982). To measure acculturative stress, we used the homesickness and perceived discrimination subscales from the Acculturative Stress Scale for International Students (ASSIS, Sandhu \& 
Asarabi, 1994), the language difficulty subscale from the Index of Life Stress (Yang \& Clum, 1995), and the Perceived Language Discrimination Scale (Wei, Ku, \& Wang, 2012). We also used a 6-item measure of psychological adaptation very similar to the PANAS (see Koenig-Lewis, Palmer, Dermody, \& Urbye, 2013), and would be relatively simple for English-learning students to understand, as well as a 4-item scale gauging life-satisfaction (Esses, Burstein, Ravanera, Hallman, \& Medianu, 2012). Finally, we used the McGill Friendship Questionnaire (Mendelson \& Aboud, 2012) to measure friendship quality for program participants at Time 2. Reliabilities for the scales we used can be seen in Table 1.

Table 1

\begin{tabular}{|c|c|c|c|}
\hline Measure & \# of Items & Time $1 \alpha$ & Time $2 \alpha$ \\
\hline Sociocultural Adaptation & 8 & .865 & .822 \\
\hline $\begin{array}{l}\text { Acculturative Stress: } \\
\text { Homesickness }\end{array}$ & 4 & .659 & .682 \\
\hline $\begin{array}{l}\text { Acculturative Stress: Language } \\
\text { Difficulty }\end{array}$ & 3 & .730 & .426 \\
\hline $\begin{array}{l}\text { Acculturative Stress: Language } \\
\text { Discrimination }\end{array}$ & 7 & .886 & .915 \\
\hline $\begin{array}{l}\text { Acculturative Stress: General } \\
\text { Discrimination }\end{array}$ & 3 & .706 & .785 \\
\hline $\begin{array}{l}\text { Psychological Adaptation } \\
\text { (Adjectives + Satisfaction) }\end{array}$ & 10 & .512 & .721 \\
\hline McGill Positive Feelings & 4 & & .761 \\
\hline McGill Satisfaction & 4 & & .820 \\
\hline $\begin{array}{l}\text { McGill Stimulating } \\
\text { Companionship }\end{array}$ & 5 & & .866 \\
\hline McGill Help & 4 & & .833 \\
\hline McGill Emotional Security & 3 & & .838 \\
\hline McGill Self Validation & 5 & & .906 \\
\hline
\end{tabular}

AS: Acculturative Stress

\section{Hypotheses Examples}

The following hypotheses were proposed:

$\mathrm{H}_{1}$ : $\quad$ We predicted that program participation would lead to an increase in sociocultural adaptation, a decrease in acculturative stress, and an increase in psychological adaptation from Time 1 to Time 2. We also predicted that program participants would score higher on these outcomes than control participants at Time 2. We used paired samples t-tests to compare the scores of program participants at 
Time 1 and Time 2 and independent samples t-tests to assess the differences between program participants and control participants at Time 2.

$\mathrm{H}_{2}$ : We predicted that at Time 2, the effect of program participation on psychological adaptation would be mediated by a reduction in acculturative stress. To test this hypothesis, we conducted a bootstrapping mediation analysis (Preacher \& Hayes, 2008).

$\mathrm{H}_{3}$ : We predicted that better friendship quality at Time 2, would predict better sociocultural adaptation, psychological adaptation, and lower acculturative stress at Time 2, controlling for Time 1 outcomes. To test this hypothesis, we used multiple regression analyses.

\section{RESULTS}

Descriptive statistics for program participants at Time 1 and Time 2, and control participants at Time 2 can be found in Table 2 .

Table 2: Descriptive Statistics for Program Group at Time 1 and Time 2, and Control Group at Time 2

\begin{tabular}{|c|c|c|c|c|c|c|c|c|c|}
\hline \multirow[b]{2}{*}{ Variable } & \multicolumn{3}{|c|}{ Program Time 1} & \multicolumn{3}{|c|}{ Program Time 2} & \multicolumn{3}{|c|}{ Control Time 2} \\
\hline & $n$ & $M$ & $S D$ & $n$ & $M$ & $S D$ & $n$ & $M$ & $S D$ \\
\hline $\begin{array}{l}\text { Sociocultural } \\
\text { Adaptation }\end{array}$ & 22 & 3.22 & 1.19 & 25 & 3.93 & 1.03 & 22 & 3.57 & 1.00 \\
\hline $\begin{array}{l}\text { Acculturative } \\
\text { Stress }\end{array}$ & 23 & 3.06 & .98 & 25 & 2.75 & .71 & 22 & 3.23 & .86 \\
\hline $\begin{array}{l}\text { Psychological } \\
\text { Adaptation }\end{array}$ & 23 & 4.78 & .63 & 25 & 5.09 & .51 & 22 & 4.63 & .93 \\
\hline
\end{tabular}

Sociocultural adaptation. As expected, program participants experienced higher sociocultural adaptation at Time 2 than at Time 1, $\mathrm{t}(21)$ $=-2.81, \mathrm{p}<.01, \mathrm{~d}=.63,95 \% \mathrm{CI}=[-1.25,-.19]$. At Time 2, we unexpectedly found that while program participants did experience higher sociocultural adaptation than control participants, this difference was not significant, $\mathrm{t}(45)=1.22, \mathrm{p}=.12 \mathrm{~d}=.36,95 \% \mathrm{CI}=[-.24, .96]$. The difference in sociocultural adaptation between the program group at Time 1 and the control group at Time 2 was not significant, $\mathrm{t}(42)=-1.08, \mathrm{p}=.143$, $\mathrm{d}=.33$, [95\% CI $=-1.03, .31]$.

Acculturative stress. As expected, program students showed a decrease in acculturative stress from Time 1 to Time 2, $\mathrm{t}(22)=2.9, \mathrm{p}=<$ $.001, \mathrm{~d}=.64,[95 \% \mathrm{CI}=.10, .58]$. Also, as expected, program students showed lower acculturative stress at Time 2, in comparison to control students, $\mathrm{t}(45)=-2.1, \mathrm{p}=<.05, \mathrm{~d}=.61,95 \% \mathrm{CI}[-.94,-.02]$. The program 
group at Time 1 and control group at Time 2 did not significantly differ in acculturative stress, $\mathrm{t}(43)=-.61, \mathrm{p}=.274, \mathrm{~d}=.18,[95 \% \mathrm{CI}=-2.88,1.54]$.

Psychological adaptation. As expected, program participants showed higher psychological adaptation at Time 2 than at Time $1, \mathrm{t}(22)=$ 1.89, $\mathrm{p}<.05, \mathrm{~d}=.57,95 \% \mathrm{CI}=[-.61, .03]$. Also, as expected, program participants showed higher psychological adaptation than control participants at Time 2, t(45) $=2.08, \mathrm{p}=<.05, \mathrm{~d}=.60,95 \% \mathrm{CI}=[.01, .92]$. The program group at Time 1 and the control group at Time 2 did not differ on psychological adaptation, $\mathrm{t}(43)=.68, \mathrm{p}=.249, \mathrm{~d}=.20,95 \% \mathrm{CI}=[-.63$, 1.27].

Mediation. We conducted a bootstrapping mediation analysis (Preacher \& Hayes, 2008), investigating the indirect effect of the program on psychological adaptation through acculturative stress. The unstandardized indirect effect was computed by multiplying two regression coefficients. The first was the regression coefficient for group (the program group coded as " 1 " and the control group coded as “ 0 ”), when entered as the sole predictor of acculturative stress, $b=-.48, t(45)=-2.10, p<.05$. The second was the regression coefficient for acculturative stress as a predictor of psychological adaptation, when group was also entered as a predictor, $\mathrm{b}=$ -.36, $\mathrm{t}(44)=-2.72, \mathrm{p}=<.01$ These two regression coefficients yielded an indirect effect of $(-.48)(-.36)=.17$. Unstandardized indirect effects were computed for each of 5,000 bootstrapped samples and the 95\% confidence interval was computed. The 95\% confidence interval ranged from .04 to .39. Thus, the indirect effect was statistically significant because the $95 \%$ confidence interval did not contain zero.

We also tested the reverse mediation model. This model considered the relationship between the program and acculturative stress at Time 2, as mediated by an increase in psychological adaptation at Time 2. With 5,000 bootstrapped samples, this mediation model yielded an indirect effect of -.19 with a $95 \%$ confidence interval ranging from -.44 to -.04. This indirect effect was also statistically significant because its confidence interval did not contain zero. These results would suggest that either of the hypothesized or reverse mediation models could be plausible.

Friendship quality. It was found that Time 2 friendship quality did not add to the prediction of the Time 2 outcomes, when the Time 1 outcomes were included in the regression model. Furthermore, the interaction of friendship quality and the Time 1 outcome did not add to prediction of the Time 2 outcome, in a regression model with the main effects. The coefficients for these regressions are reported below in Table 3. We next decided to examine the correlation between friendship quality at Time 2 and outcomes at Time 1. Those correlations suggested that students who had higher friendship quality at Time 2 had lower sociocultural adaptation at Time $1, \mathrm{r}(20)=-.456, \mathrm{p}<.05$, and higher acculturative stress 
at Time $1, \mathrm{r}(21)=.294, \mathrm{p}=.087$. Overall, these findings suggest that perhaps the students who felt they needed to improve the most at Time 1 , reported the greatest degree of closeness to their mentors at Time 2.

Table 3: Regression Models with Friendship Quality Predicting Time 2 Acculturation Outcomes, Controlling for Time 1 Outcomes

\begin{tabular}{|c|c|c|c|c|c|c|}
\hline & \multicolumn{2}{|c|}{$\begin{array}{l}\text { Time } 2 \\
\text { Sociocultural } \\
\text { Adaptation }\end{array}$} & \multicolumn{2}{|c|}{$\begin{array}{l}\text { Time } 2 \\
\text { Acculturative } \\
\text { Stress }\end{array}$} & \multicolumn{2}{|c|}{$\begin{array}{l}\text { Time } 2 \\
\text { Psychological } \\
\text { Adaptation }\end{array}$} \\
\hline & $B$ & $S E$ & $B$ & $S E$ & $b$ & $S E$ \\
\hline $\begin{array}{l}\text { Friendship } \\
\text { Quality }\end{array}$ & .014 & .207 & .013 & .083 & -.004 & .097 \\
\hline $\begin{array}{l}\text { Time } 1 \\
\text { Sociocultural } \\
\text { Adaptation }\end{array}$ & $.416 *$ & .210 & & & & \\
\hline $\begin{array}{l}\text { Time } 1 \\
\text { Acculturative } \\
\text { Stress }\end{array}$ & & & $.615^{* * * *}$ & .100 & & \\
\hline $\begin{array}{l}\text { Time } 1 \\
\text { Psychological } \\
\text { Adaptation }\end{array}$ & & & & & .176 & .344 \\
\hline
\end{tabular}

\section{DISCUSSION}

The pattern of results obtained suggests that the mentorship program developed for this research was effective at facilitating positive changes for international students on the outcomes measured over time. The pairedsamples comparisons for program participants suggest that they experienced increases on sociocultural and psychological adaptation, and a reduction in acculturative stress over time. The independent-samples comparisons suggest that in comparison to a control group, the program students, who had the opportunity to make a host-Canadian friend over the course of the semester, showed higher psychological adaptation and lower acculturative stress at the end of the semester.

One result that was not consistent with hypotheses 1 or 2 was the non-significant difference between program and control students at Time 2 on sociocultural adaptation. A potential explanation for this non-significant difference may be related to the fact that many of the control participants lived in homestay, whereas this was not the case for program participants. Literature on homestay suggests that homestay families can serve as an instrumental resource that can assist students in learning the host language 
(Schmidt-Reinhardt \& McKnight, 2004) and become more familiar with the host country's customs and social and political climate (Shiri, 2015). Given that many of the students in the control group lived with homestay families, it may be the case that homestay could provide students an effective source of social support, and in the present context, the control participants may have received additional social support from homestay families.

\section{Directions for further research}

The results of the present work provide several interesting and potentially important grounds for future research. First, the program was only conducted over a period of three months and longer-term effects were not examined. It would be important to determine whether the outcomes observed here are maintained over a longer period of time following the completion of the program. Do students go on to form more social connections with hosts, having participated in the mentorship program? Future research could adopt more time points to investigate this. Additional time points could also allow for the temporal separation of acculturative stress and psychological adaptation. Although acculturative stress is typically seen as an antecedent of psychological adaptation (Berry, 2006; Zhang \& Goodson, 2011), the current results suggest that perhaps a clearer picture as to which of the two mediation models examined in this study is more appropriate is needed. Does program participation enhance psychological adaptation through a reduction in acculturative stress, the opposite, or are they mutually reinforcing? Also, as discussed, future research should investigate the extent to which homestay families can serve as meaningful sources of social support, and the extent to which they can influence sociocultural adaptation. In further study, the effects of the program on the mentors who participated should certainly be examined. Participating in a mentorship program could encourage mentors to improve their intercultural awareness and communication, both of which are important skills for university graduates to possess when they are entering the workforce in a diverse country like Canada. Finally, although the results of present study support the effectiveness of mentorship programs, they were obtained with a small sample. A future replication could therefore be conducted with a larger sample size, and also include program and control participants from the same academic cohort completing measures at all time points.

\section{Practical implications}

As the present research produced results that suggested it was successful at helping international students' acculturation outcomes, it may be worthwhile for similar programs in the future to consider the manner in which this program was structured and delivered. Pairs met each week for 
the duration of the semester and while pairs were given a semi-structured guide on how to spend their time together, they were not given a rigorous checklist of activities to complete. The program seemed to function well when participants were given the freedom to find activities that they enjoyed together. The program also involved interactive activities that engaged all participants during the group meetings. The group meetings were especially beneficial in that they served the function of keeping pairs on track in reminding them to meet regularly. Therefore, future renditions of similar programs may consider allowing pairs the freedom to find and engage in activities they enjoy while offering structured group meetings with interactive activities every few weeks.

\section{Limitations}

One potential limitation with the present sample is that many of the students were from China. Past findings suggest that international students originating from more culturally distant regions (e.g. Asia, Middle East) may experience greater challenges in adjusting to a Western university as these regions share fewer commonalities with Western culture than regions like Europe or South America (Poyrazli \& Kavanaugh, 2006; Zhang \& Goodson, 2011). Therefore, the benefits observed from the predominantly Asian sample of students in the present study may or may not generalize to the cultural groups of students whose heritage cultures are more similar to Western culture. Indeed, the Canadian Bureau of International Education report revealed that only 28\% of students from the Middle East and 31\% of students from East Asia reported friendships with Canadian students, while $50 \%$ of students from Latin America and the Caribbean, and over $50 \%$ of European students, reported friendships with Canadians (CBIE, 2015). Thus, some ethnic groups of international students have an easier time connecting with hosts than other groups. The country of origin of international students and how it may interact with potential social or language barriers remains an important question for further study.

\section{CONCLUSION}

The present research makes an important contribution to the literature on international students as it utilized a quasi-experimental approach in order to assess the influence of friendships with host-national students on both the social and psychological domains of international students' acculturation to university. Much of the past work, which pointed to the benefits of hostnational friendships for international students, was correlational (see Zhang \& Goodson, 2011), and did not assess a variety of outcomes in one study (Smith \& Khawaja, 2011). The results of the present work can therefore be used to provide insight into a potential causal link between friendships with 
host-national students and better adaptation outcomes. As more and more international students are welcomed into countries like Canada, research is needed to determine the types of initiatives that can best facilitate positive outcomes for international students. The findings of the present work support the effectiveness of mentorship programs while also offering suggestions for future research.

\section{REFERENCES}

Abe, J., Talbot, D. M., \& Geelhoed, R. J. (1998). Effects of a peer program on international student adjustment. Journal of College Student Development, 39(6), 537-547. Retrieved From: http://search.proquest.com

Association of Universities and Colleges of Canada. (2014). Canada's universities in the world: AUCC internationalization survey. Retrieved from: http://www.aucc.ca/wp-content/uploads/2014/12/internationalizationsurvey-2014.pdf

Bohm, Davis, Meares, \& Pearce (2002). Global student mobility 2025: Forecasts of the global demand for international education. Canberra, Australia: IDP Education. Retrieved from: http://www.idp.com/16aiecpapers/program/ thursday/marketing2/Bohm_2025Media_p.pdf

Berry, J. W. (2006). Stress perspectives on acculturation. In Sam, D. L. and Berry, J. W. (Eds.), The Cambridge handbook of acculturation psychology (pp. 43-57). Cambridge, UK: Cambridge University Press.

Canadian Bureau for International Education (2015). The integration challenge: Connecting international students with their Canadian peers. Retrieved from: http://www.cbie.ca/media-centre/publications/cbie-research-in-brief/

Davies, K., Tropp, L. R., Aron, A., Pettigrew, T. F., \& Wright, S.C. (2011). Crossgroup friendships and intergroup attitudes: A meta-analytic review. Personality and Social Psychology Review, 15(4), 332-351. doi:10.1177/108886831141110

Esses, V. M., Burstein, M., Ravanera, Z., Hallman, S., \& Medianu, M. (2013). Alberta settlement outcomes survey. Retrieved from: https://work.alberta.ca/documents/alberta-outcomes-settlement-surveyresults.pdf

Furnham, A., \& Bochner, S. (1982). Social difficulty in a foreign culture: An empirical analysis of culture shock. In Bochner, S. (Ed.), Cultures in Contact. Toronto, Pergamon Press.

Gresham, R., \& Clayton, V. (2011). Community connections: A programme to enhance domestic and international students' educational experience. Journal of Higher Education Policy and Management, 33(4), 363-374. doi: 10.1080/1360080X.2011.585736

Hechanova-Alampay, R., Beehr, T. A., Christiansen, N. D., \& Van Horn, R. K. (2002). Adjustment and strain among domestic and international student

sojourners: A longitudinal study. School Psychology International, 23(4), 458-474. doi: 10.1177/0143034302234007

Howitt, D. (2013). Introduction to Qualitative Methods in Psychology. Toronto, Pearson. 
ICEF Monitor (2014). The state of international student mobility in 2015. Retrieved from: http://monitor.icef.com/2015/11/the-state-of-international-studentmobility-in-2015/

Koenig-Lewis, N., Palmer, A., Dermody, J., \& Urbye, A. (2014). Consumers’ evaluations of ecological packaging - rational and emotional approaches. Journal of Environmental Psychology, 37, 94-105. doi: 10.1016/j.jenvp.2013.11.009

Li, A., \& Gasser, M. B. (2005). Predicting Asian international students' sociocultural adjustment: A test of two mediation models. International Journal of Intercultural Relations, 29(5), 571-576. doi: 10.1016/j.ijintrel.2005.06.003

Masgoret, A., \& Ward, C. (2006). Culture learning approach to acculturation. In Sam, D. L. and Berry, J. W. (Eds.), The Cambridge handbook of acculturation psychology, 58-77. Cambridge, UK: CUP.

Mendelson, M. J. \& Aboud, F. (2012). McGill Friendship Questionnaire Respondent's affection (MFQ-RA). Measurement Instrument Database for the Social Science. Retrieved from www.midss.ie

Poyrazli, S., \& Kavanaugh, P. R. (2006). Marital status, ethnicity, academic achievement, and adjustment strains: The case of graduate international students. College Student Journal, 40(4), 767-780.

Preacher, K. J., \& Hayes, A. F. (2008). Asymptomatic and resampling strategies for assessing and comparing indirect effects in multiple mediation models. Behavior Research Methods, 40(3), 879-891. doi: 10.3758/BRM.40.3.897.

Rasmi, S., Safdar, S. \& Lewis, J.R. (2009). A longitudinal examination of the MIDA Model with international students (42-57). In A. Chybicka, S. Safdar, \& A. Kwiatkowska (Eds.). Culture and Gender: An Intimate Relation. Gdanskie Wydawnictwo Psychologiczne: Gdansk, Poland.

Sam, D. L. (2006). Acculturation: conceptual background and core concepts. In Sam, D. L. and Berry, J. W. (Eds.), The Cambridge handbook of acculturation psychology (pp. 11-26). Cambridge, UK: Cambridge University Press.

Sandhu, D. S. \& Asarabi, B. R. (1994). Development of an acculturative stress scale for international students. Psychological Reports, 75, 435-448. doi: 10.2466/pr0.1994.75.1.435

Schmidt-Reinhardt, B. C., \& McKnight, S. M. (2004). The homestay component of study abroad: Three perspectives. Foreign Language Annals, 37(2), 254262. doi: 10.1111/j.1944-9720.2004.tb02198.x

Siri, S. (2015). The homestay in intensive language study abroad: Social networks, language socialization, and developing intercultural competence. Foreign Language Annals 48(1), 5-25. doi: 10.1111/flan.12127

Smith, R. A., \& Khawaja, N. G. (2011). A review of the acculturation experience of international students. International Journal of Intercultural Relations, 35(6), 699-713. doi: 10.1016/j.ijintrel.2011.08.004

Ward, C. \& Kennedy, A. (1993). Where's the culture in cross-cultural transition? Comparative studies of sojourner adjustment. Journal of Cross-cultural Psychology, 24(2), 221-249. doi: 10.1177/0022022193242006

Ward, C., Bochner, S., \& Furnham, A., (2001). The psychology of culture shock. Second edition. East Sussex, UK: Routledge. 
Wei, M., Ku, T., \& Wang, K. T. (2012). A development and validation of the perceived language discrimination scale. Cultural Diversity and Ethnic Minority Psychology, 18(4), 340-351. doi: 10.1037/a0029453

Westwood, M. J., \& Barker, M. (1990). Academic achievement and social adaptation among international students: A comparison groups study of the peer-pairing program. International Journal of Intercultural Relations, 14(2), 251-263. doi: 10.1016/0147-1767(90)90008-K

Yang, B. \& Clum, G. A. (1995). Measures of life stress and social support specific to an Asian student population. Journal of Psychopathology and Behavioral Assessment, 17(1), 51-67, doi: 10.1007/BF02229203

Ying, Y., \& Han, M. (2006). The contribution of personality, acculturative stressors, and social affiliation to adjustment: A longitudinal study of Taiwanese international students in the United States. International Journal of Intercultural Relations, 30(5), 623-635. doi: 10.1016/j.ijintrel.2006.02.001

Zhang, J. \& Goodson, P. (2011). Predictors of international students' psychosocial adjustment to life in the United States: A systematic review. International Journal of Intercultural Relations, 35(2), 139-162. doi: 10.1016/j.ijintrel.2010.11.011

ACKNOWLEDGEMENTS: We are grateful to Dr. Lorne Campbell for his insights on the methodology of this project. We are also very appreciative of the Western English Language Centre, the Student Success Centre, and CultureWorks for their support in helping us with participant recruitment.

CLINT THOMSON, MSc, is a Senior Research Analyst in the Office of University Planning and Analysis at Vancouver Island University. He completed an MSc degree in Social Psychology at The University of Western Ontario in 2016. His research and professional interests include program evaluation within higher education institutions, international student issues, and mixed methods research.Email: Clint.Thomson@viu.ca

VICTORIA M. ESSES, $\mathrm{PhD}$, is a Professor of Psychology at The University of Western Ontario. She is also the Principal Investigator of the Pathways to Prosperity Partnership, http://p2pcanada.ca/

Manuscript submitted: June 14, 2016

Manuscript Revised: September 5, 2016 Accepted for publication: October 13, 2016 